\title{
Translator's Note
}

For this text, I have broken with a long-established tradition in Agamben translations by declining to mark the distinction between two pairs of terms: dirittollegge and poterelpotenza (conventionally translated as juridical order/law and power/potential, respectively). In neither of these texts is Agamben exploring the conceptual problems that motivated the technical usage of these pairs, and hence translating them in the conventional way struck me as unidiomatic and distracting. Nevertheless, Agamben's usage of the respective pairs is systematic within this text and can be tracked fairly easily based on the sense. Diritto appears exclusively in "The Mystery of the Church" and always refers to "law in general" (for instance, diritto naturale e diritto positivo is translated as "natural law and positive law" rather than "natural juridical order and positive juridical order"), and every use of 
"law" in the context of the exposition of the biblical text corresponds to legge; potere refers to political power in an abstract sense (e.g., constitutional powers or state powers), while potenza refers to concrete political "powers" in the sense of visible institutions (the Roman Empire, the Catholic Church, etc.). The only exception to the latter rule comes in Agamben's rendering of 2 Thessalonians 2:9, where Satan is said to use "all power" (ogni potenza).

For Greek terms, I have supplied macrons, which do not appear in Agamben's Italian text. The lack of macrons sometimes creates ambiguity as to whether we are dealing with the katechōn (the personal form: "the one who restrains") or the katechon (the impersonal form: "what restrains"), and I have opted to add or omit the macron depending on what seemed to me to be the more likely sense in any given case. Finally, I regret that there was no possible translation for the subtitle of the second essay that did not introduce a rhyme that does not exist in the Italian.

I would like to thank Carlo Salzani for checking my translation against the Italian text and to extend my continued gratitude to Emily-Jane Cohen and the entire staff of Stanford University Press. 